\title{
PENGARUH PEMANASAN BAHAN BAKAR DENGAN MEMANFAATKAN ALIRAN OLI MESIN TERHADAP KINERJA MESIN SEPEDA MOTOR
}

\author{
Nur Akhmad Triwibowo, Faisal Nurriqza, Teguh Wibowo \\ Departemen Teknik Mesin \\ Sekolah Tinggi Teknologi Adisutjipto \\ J1. Janti Blok R Lanud Adisutjipto Yogyakarta. \\ Email : akhmadtriwibowo@gmail.com
}

\section{Abstract}

The increase of transportation need affects an increase in the need for fuel oil. The high fuel consumption can be controlled by refining the combustion process in the combustion chamber, one of them is by heating up the fuel. It could be one way to save fuel. The tests conducted on the Yamaha Jupiter MX assemblied in 2011 on the power, torque and fuel consumption by heating and without heating the fuel. The variations of engine speed used were $5000 \mathrm{rpm}, 6000$ $\mathrm{rpm}, 7000 \mathrm{rpm}$ and $8000 \mathrm{rpm}$. The results indicated that the fuel heating through helical coil heat exchangers with oil fluid could increase the average power (7.03\%) and the average torque (5.83\%) at $6000 \mathrm{rpm}-8000 \mathrm{rpm}$ and decrease the average spesific fuel consumption (17.13\%) at $6000 \mathrm{rpm}-8000 \mathrm{rpm}$.

Keywords-power, torque, fuel, helical coil heat exchanger

\section{Pendahuluan}

Proses pembakaran pada ruang bakar dipengaruhi oleh temperatur, kerapatan campuran, komposisi aliran udara dan turbulensi yang ada pada campuran bahan bakar dan udara tersebut untuk dibakar (Suyanto, 1989). Apabila temperatur campuran udara dan bahan bakar naik, maka semakin mudah campuran udara dan bahan bakar tersebut untuk terbakar. Hubungan pemanasan bahan bakar dengan konsumsi bahan bakar yaitu apabila dalam proses pencampuran udara terdapat sebagian bahan bakar yang tidak menguap maka distribusi campuran menjadi sangat tidak homogen. Campuran tersebut menjadi kurus, yang berarti bahwa perbandingan udara lebih banyak dari pada bahan bakar sehingga sulit untuk terbakar pada ruang bakar yang mengakibatkan unjuk kerja mesin berkurang.

Kondisi seperti ini dapat berakibat pada konsumsi bahan bakar menjadi tidak efektif terhadap kebutuhan mesin dan menurunnya unjuk kerja mesin, sehingga dapat diasumsikan bahwa bila bahan bakar dipanaskan hingga dibawah temperature fire point maka bahan bakar lebih cepat menguap. Bahan bakar akan lebih mudah bercampur dengan udara dan pembakaran menjadi lebih baik. Bahan bakar yang diberi treatment panas dapat menjadi salah satu cara untuk menghemat bahan bakar.

2. Metode Penelitian

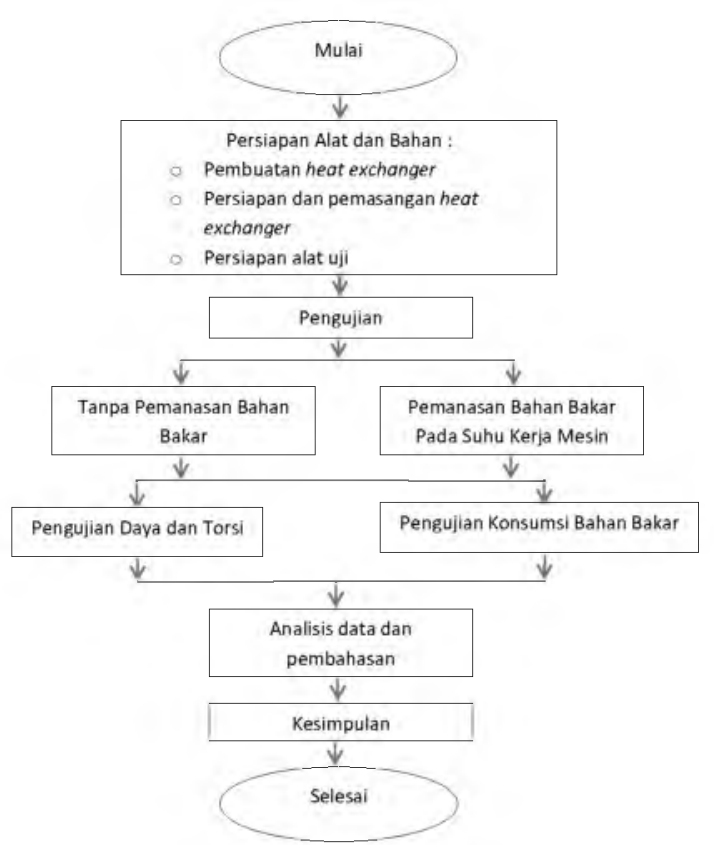

Gambar 1. Diagram Alir Penelitian 
Bahan dan peralatan yang digunakan antara lain :

1. Tachometer

2. Termokopel dan pembacanya

3. Dynometer

4. Gelas ukur

5. Stopwatch

6. Motor Yamaha Jupiter $\mathrm{Mx}, 4$ langkah, 4 Valve, SOHC, $135 \mathrm{cc}$, dengan sistem bahan bakar karburator.

7. Plat alumunium tebal $12 \mathrm{~mm}$

8. Pipa kapiler $1 / 4$ inc $1000 \mathrm{~mm}$

9. Selang $1 / 4$ inc dipilih bahan yang tahan panas dan tahan tekanan.

10.Plat galvanis tebal $0,5 \mathrm{~mm}$ dengan $\mathrm{P} \times \mathrm{l}=300 \mathrm{~mm} \times 300 \mathrm{~mm}$

11.Kawat las kuningan

12. Bahan Bakar Pertalite

13. Alumunium Foil/heat insulator.

14.Pipa buret.

\section{Pembuatan Heat Exchanger}

Heat exchanger didesain menggunakan jenis helical coil dengan skema sebagai berikut :

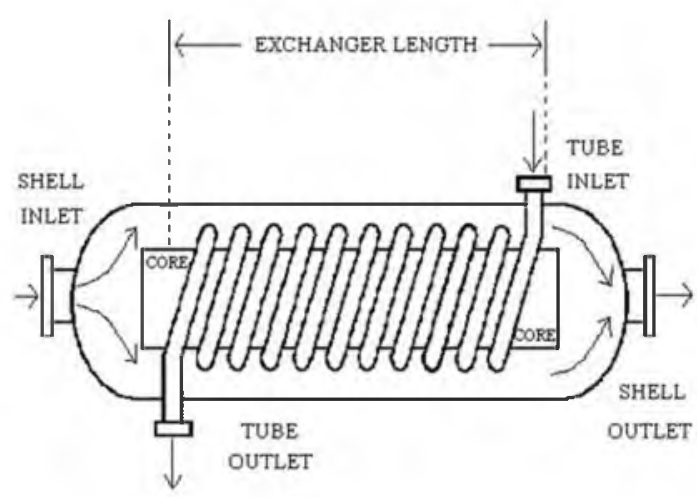

Gambar 2. Skema Heat Exchanger Jenis Helical Coil

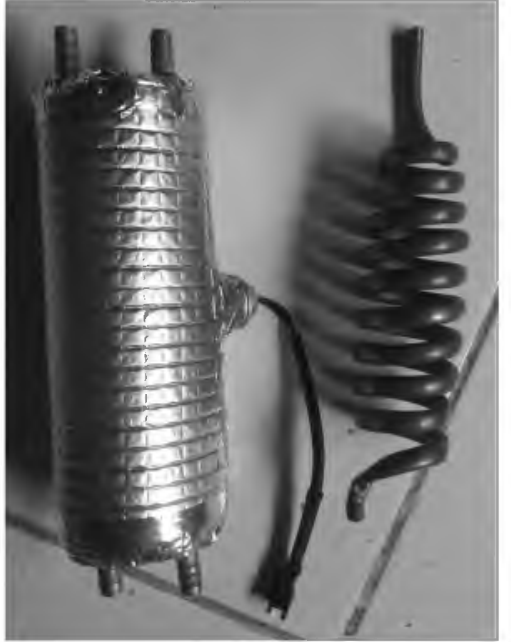

Gambar 3. Heat Exchanger Yang Telah Diproduksi

Pemasangan Heat Exchanger

Heat Exchanger dipasang pada motor Yamaha Jupiter MX produksi tahun 2011 dengan skema sebagai berikut:

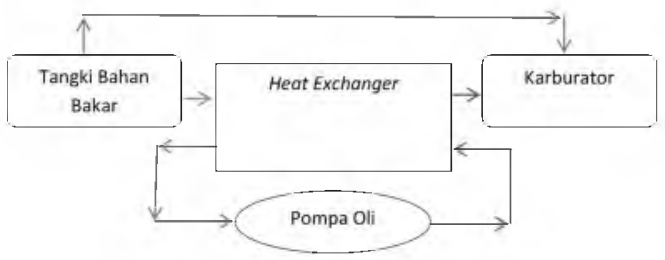

Gambar 4. Skema Pemasangan Heat Exchanger

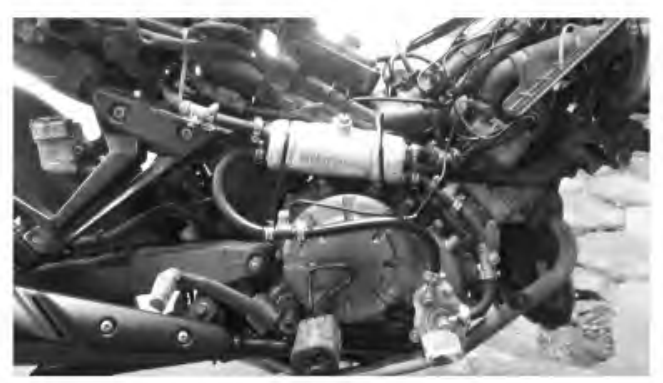

Gambar 5. Pemasangan Heat Exchanger Pada Motor 


\section{Pengujian}

Beberapa pengujian dilakukan untuk mendapatkan data kinerja motor berupa daya, torsi dan specific fuel consumption untuk motor tanpa pemanasan bahan bakar dan motor dengan menggunakan pemanasan bahan bakar. Pemanasan bahan bakar memanfaatkan aliran oli mesin yang relatif panas melalui heat exchanger tipe helical coil. Pengujian daya dan torsi menggunakan mesin dynotest di bengkel Mototech. Selain itu dilakukan pengujian konsumsi bahan bakar dengan menggunakan gelas ukur, pipa buret, stopwatch dan tachometer untuk mendapatkan nilai specific fuel consumption.

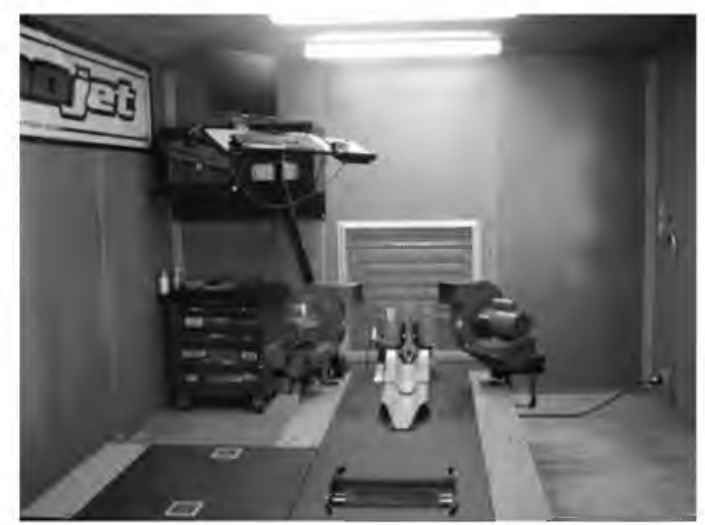

Gambar 6. Ruang dan Peralatan Dyno Test

\section{Hasil dan Pembahasan}

3.1 Hasil Pengujian Daya Dan Torsi Terhadap Putaran Mesin

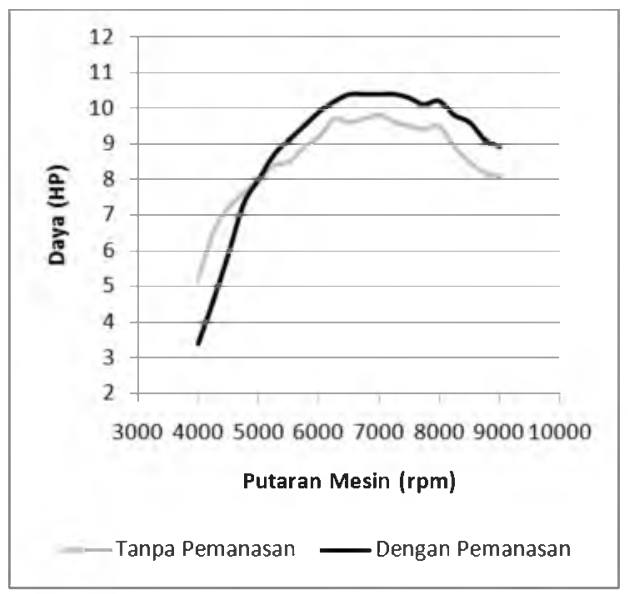

Gambar 7 Grafik Daya vs Putaran Mesin

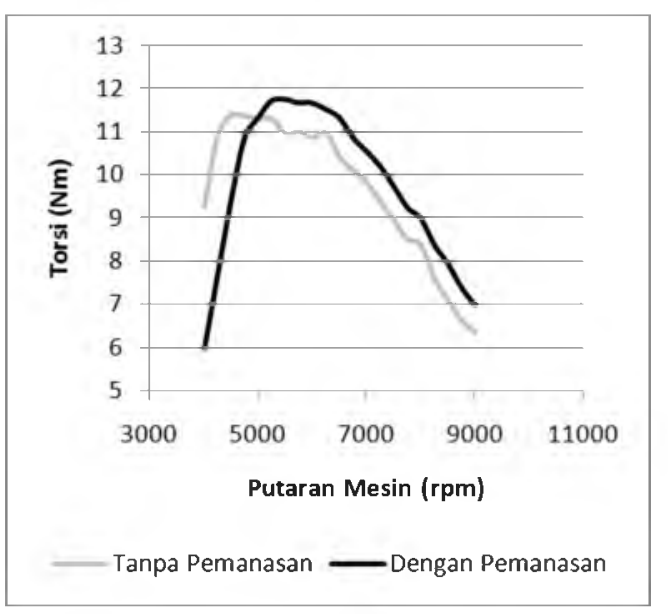

Gambar 8 Grafik Torsi vs Putaran Mesin

Gambar 7 dan 8 merupakan grafik hubungan antara daya dan torsi terhadap variasi putaran mesin yang telah ditentukan. Dari grafik tersebut, baik daya maupun torsi dapat kita lihat bahwa pemanasan bahan bakar dapat berpengaruh terhadap daya dan torsi yang dihasilkan oleh motor bakar. Dapat dilihat pada Gambar 7 kenaikan daya terjadi dengan adanya pemanasan bahan bakar dengan media helical coil heat exchanger mulai $6000 \mathrm{rpm}$ yaitu sebesar 7,6 $\%$, kemudian $7000 \mathrm{rpm}$ sebesar $6,12 \%$ dan $8000 \mathrm{rpm}$ sebesar $7,37 \%$ sedangkan pada $5000 \mathrm{rpm}$ tidak terjadi kenaikan daya.Selain itu, pada Gambar 8 dapat dilihat terdapat kenaikan torsi dengan adanya pemanasan bahan bakar dengan media helical coil heat exchanger mulai $6000 \mathrm{rpm}$ yakni sebesar $7,5 \%$, kemudian pada $7000 \mathrm{rpm}$ sebesar $2,84 \%$ dan pada $8000 \mathrm{rpm}$ sebesar $7,15 \%$. Hal ini disebabkan karena saat kondisi pemanasan bahan bakar, temperatur campuran udara dan bahan bakar juga naik dan juga membantu pengkabutan pada nosel karburator karena temperatur bahan bakar mendekati titik penguapan jadi campuran lebih homogen. Proses pembakaran didalam silinder dipengaruhi oleh: temperatur, kerapatan campuran, komposisi, dan turbulensi yang ada pada campuran (Suyanto, 1989). Apabila temperatur campuran bahan bakar dengan udara naik, maka semakin mudah campuran bahan bakar dengan udara tersebut untuk terbakar. 
Dengan temperatur yang cukup campuran bahan bakar dalam hal ini pertalite dengan udara akan lebih mudah terbakar sehingga pembakaran lebih efektif dan efisien.

Salah satu karakteristik bahan bakar yang harus dimiliki bahan bakar adalah penguapan (Suyanto, 1989). Penguapan di sini yang dimaksud adalah kemampuan bahan bakar untuk berubah dari bentuk cair menjadi gas. Karena bahan bakar yang masuk ke dalam silinder harus berbentuk gas yang bercampur dengan udara maka sifat mudah menguap dari bensin atau pertalite ini sangat diperlukan. Tingkat kemudahan menguap yang dimiliki bahan bakar untuk motor bensin harus tepat sesuai dengan kebutuhan motor tersebut, yaitu motor mudah distater, cepat memanaskan motor, percepatan yang halus, dan irit penggunaan bahan bakar.Pemanasan bahan bakar menaikkan temperatur bahan bakar mendekati temperatur penguapan, hal itu dapat membantu pengkabutan bahan bakar pada nosel spuyer karburator sehingga bahan bakar lebih mudah mengabut dan lebih mudah bercampur dengan udara.

Campuran bahan bakar kemudian dibakar pada akhir langkah kompresi dengan memanfaatkan percikan busi. Sekalipun perbandingan campuran sudah bagus, bila sebagian bahan bakar tidak dapat menguap, maka akan mengakibatkan campuran menjadi kurus, sehingga akan menghasilkan suatu pembakaran yang tidak sempurna.

Pada putaran mesin rendah $(5000$ rpm) tidak terjadi kenaikan torsi. Hal ini disebabkan karena pada putaran mesin tersebut pengukuran pada dyno meter belum stabil (mengalami slip pada putaran awal). Pada putaran mesin tersebut dengan adanya pemanasan juga membutuhkan kerja pompa yang lebih besar, sehingga antara rugi-rugi mekanis dengan kenaikan tenaga yang dihasilkan lebih besar rugi-ruginya pada putaran mesin rendah.
3.2 Hasil Pengujian Konsumsi Bahan Bakar Terhadap Putaran Mesin Yang Ditentukan

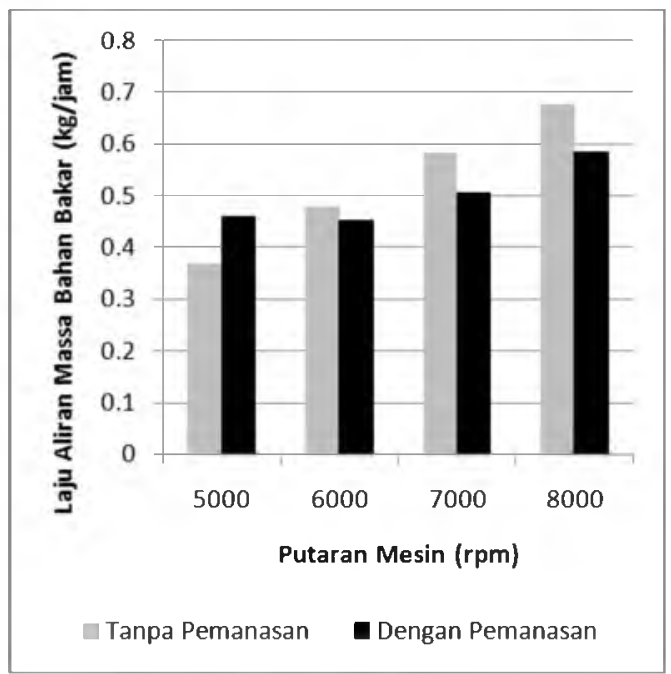

Gambar 9 Laju aliran massa bahan bakar

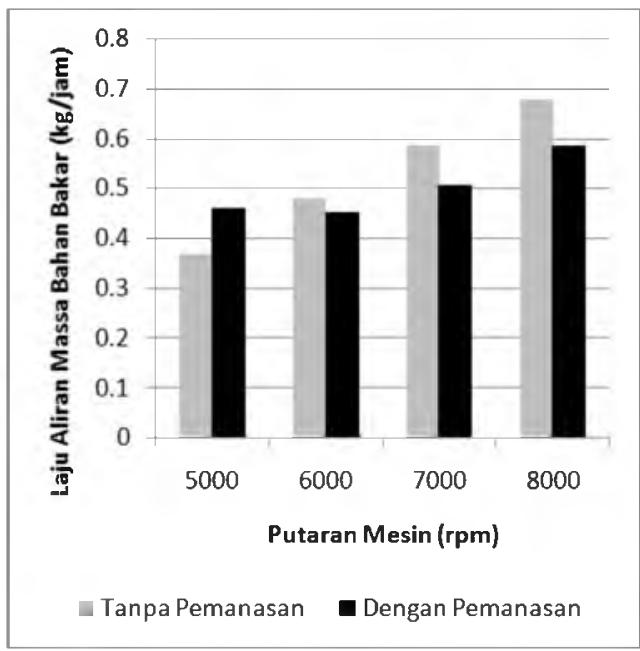

Gambar 10 Grafik Spesific Fuel Consumption

Dari grafik Spesific Fuel Consumption pada Gambar 10, dapat kita lihat bahwa pada $5000 \mathrm{rpm}$ konsumsi bahan bakar spesifik saat dilakukan pemanasan dengan media helical coil heat exchanger mengalami kenaikan konsumsi bahan bakar spesifik sebesar $24,2 \%$, kemudian pada $6000 \mathrm{rpm}$ terjadi penurunan konsumsi bahan bakar sebesar $12,86 \%$, pada $7000 \mathrm{rpm}$ terjadi 
penurunan konsumsi bahan bakar sebesar $18,75 \%$, dan pada $8000 \mathrm{rpm}$ terjadi penuruan sebesar $19,79 \%$. Seiring dengan kenaikan daya dan torsi seperti pada Gambar 7 dan 8 ternyata pemanasan bahan bakar juga mempengaruhi konsumsi bahan bakar. Dapat dilihat pada Gambar 10, penurunan konsumsi bahan bakar spesifik terjadi pada kondisi dengan adanya pemanasan bahan bakar.

Kenaikan daya juga mempengaruhi konsumsi bahan bakar spesifik, berdasarkan rumus semakin tinggi dayanya maka juga semakin rendah konsumsi bahan bakarnya. Tetapi hal ini juga tergantung terhadap laju aliran massa bahan bakarnya. Laju aliran massa bahan bakar dapat dilihat pada gambar 9. Dari gambar 7 dan 8 dapat kita lihat bahwa dengan adanya pemanasan bahan bakar melalui Heat Exchanger membuat daya dari motor naik dan laju aliran bahan bakar turun, sehingga berdasarkan rumus untuk mencari spesific fuel consumption, maka spesific fuel consumptionnya turun dengan adanya pemanasan bahan bakar seperti pada gambar 10. Turunnya laju aliran massa bahan bakar dapat disebabkan karena pemanasan melalui heat exchanger dengan memanfaatkan panas dari fluida oli, dapat membantu proses pengkabutan di spuyer nosel atau karburator sehingga bahan bakar mendekati titik penguapannya. Tetapi, untuk konsumsi bahan bakar riil antara naiknya daya dan konsumsi bahan bakar tidak berhubungan secara langsung.

Pembakaran yang sempurna dapat terjadi bila perbandingan campuran antara udara dan bahan bakar masih dalam batas yang ditentukan dalam kondisi tertentu (Soenarto;1995). Perbandingan campuran bila diperlukan tenaga maksimum adalah berkisar antara 12 - 13 : 1. Jadi lebih gemuk dari campuran teoritis yang dibutuhkan untuk dapat terjadinya pembakaran yang sempurna yaitu $15: 1$. sekalipun perbandingan campuran sudah bagus, bila sebagian bahan bakar tidak dapat menguap, maka akan mengakibatkan campuran menjadi kurus, sehingga akan menghasilkan suatu pembakaran yang tidak sempurna. Dalam hal ini selain memboroskan bahan bakar, juga gas buang akan banyak mengandung karbonmonoksida (CO) yang beracun dan hidrokarbon ( $\mathrm{HC}$ ) yang tidak terbakar.

Kenaikan konsumsi bahan bakar spesifik pada rpm rendah, disebabkan karena pada saat putaran mesin rendah bukaan katup karburator tidak terbuka penuh atau hanya sebagian, sehingga pada grafik $\mathrm{P}-\mathrm{v}$ siklus otto riil dapat dilihat bahwa tekanan pada saat langkah hisap pada bukaan katup sebagian lebih rendah. Pada bukaan katup sebagian gaya pengereman pada langkah hisap lebih tinggi, ditambah dengan adanya helical coil heat exchanger kerja pompa menjadi lebih tinggi sehingga pada saat putaran rendah rugi-rugi yang dihasilkan pun lebih tinggi. Rugi-rugi yang tinggi ini meningkatkan kebutuhan bahan bakar agar menghasilkan daya yang cukup untuk mempertahankan agar mesin tetap hidup, dengan adanya pemanas pengkabutan juga lebih sempurna sehingga campuran bahan bakar pun harus lebih gemuk dan akibatnya pada konsumsi bahan bakar menjadi lebih boros dibandingkan dengan tanpa pemanasan. Untuk mengatasinya mungkin dapat dilakukan penyetelan ulang campuran udara sehingga pada putaran mesin rendah daya yang dihasilkan cukup atau sebanding dengan rugi-rugi yang dihasilkan dari pemasangan helical coil heat exchanger.

Saat sedang melakukan penyetelan campuran udara dan bahan bakar, biasanya kita memutar-mutar setelan angin sampai mendapatkan putaran mesin tertinggi.Pada saat putaran tertinggi itulah terjadi pembakaran yang sempurna (stoikiometri). Sedangkan dibawah atau diatas putaran mesin tersebut dapat terjadi pembakaran yang tidak sempurna(biasanya terlalu kurus), bisa jadi lebih gemuk pada putaran mesin rendah dan lebih kurus pada putaran mesin yang lebih tinggi. Adanya pemanasan bahan bakar membuat campuran lebih gemuk 
karena mesin membutuhkan daya yang lebih untuk menggerakkan pompa oli dengan adanya helical coil heat exchangerdan melawan gaya pengereman pada piston saat melakukan langkah hisap pada putaran mesin rendah. Sedangkan pada putaran mesih lebih tinggi kenaikan daya yang dihasilkan juga lebih tinggi dan gaya pengereman piston juga berkurang (dapat dilihat pada diagram P-v siklus otto riil) sehingga membuat konsumsi bahan bakar lebih rendah dan daya naik.

Penurunan daya dan naiknya konsumsi bahan bakar pada putaran mesin rendah juga dapat disebabkan karena pada putaran rendah temperatur oli untuk memanaskan bahan bakar kurang atau tidak terlalu signifikan sehingga pemanasan hanya menambah rugi-rugi mekanis saja. Dapat dilihat pada halaman lampiran bahwa pada putaran mesin rendah suhu cenderung lebih rendah daripada saat putaran mesin lebih tinggi. Sedangkan pada putaran mesin lebih tinggi (dalam penelitian ini $6000 \mathrm{rpm}-8000$ rpm), pemanasan bahan bakar membuat temperatur bahan bakar lebih optimal mendekati titik penguapan sehingga bahan bakar lebih mudah menguap, membantu proses pengkabutan bahan bakar sehingga campuran udara dan bahan bakar lebih ideal dibanding tanpa pemanasan pada putaran tinggi.

\section{Kesimpulan}

Berdasarkan penelitian "Pengaruh Pemanasan Bahan Bakar Dengan Memanfaatkan Aliran Oli Mesin Pada Kinerja Mesin Sepeda Motor", dapat diambil beberapa kesimpulan sebagai berikut :

a. Pemanasan bahan bakar dengan memanfaatkan aliran oli mesin menggunakan heat exchanger berbentuk helical coil dapat meningkatkan daya rata-rata $(7,03 \%)$ dan torsi rata-rata $(5,83 \%)$ pada $6000 \mathrm{rpm}-8000 \mathrm{rpm}$. Hal ini disebabkan karena pemanasan membantu pengkabutan bahan bakar sehingga campuran bahan bakar dan udara lebih homogen. Selain itu, pemanasan bahan bakar menaikkan temperatur campuran udara dan bahan bakar saat masuk ke dalam ruang bakar mendekati temperatur pembakaran sehingga pembakaran lebih efisien.

b. Pemanasan bahan bakar dengan media helical coil heat exchanger dengan fluida oli dapat menurunkan konsumsi bahan bakar spesifik ratarata $(17,13 \%)$ pada $6000 \mathrm{rpm}-$ $8000 \mathrm{rpm}$. Hal ini disebabkan karena pembakaran yang lebih efisien dapat menurunkan konsumsi bahan bakar spesifik.

\section{Saran}

Penelitian ini bisa dilanjutkan dengan melakukan optimasi perpindahan panas yang terjadi di heat exchanger.

\section{Ucapan Terima kasih}

Penulis mengucapkan terima kasih kepada Pusat Penelitian dan Pengabdian pada Masyarakat (P3M) Sekolah Tinggi Teknologi Adisutjipto yang telah memberi dukungan financial terhadap penelitian ini.

\section{DAFTAR PUSTAKA}

[1] Lesmono,Jhon Arif Eko.,2016, Jurnal Teknik Mesin|Vol 4, No 02,Pengaruh Pemanfaatan Gas Buang Sebagai Pemanas Intake Manifold Dengan Variasi Selubung Pemanas Terhadap Performa Mesin Supra X Tahun 2002.

[2] Mulyono, Sugeng., 2014, Pengaruh Penggunaan dan Perhitungan Efisiensi Bahan Bakar Premium dan Pertamax Terhadap Unjuk Kerja Motor Bakar Bensin, jurnal teknologi terpadu no.1 vol.2 Politeknik Balikpapan, Balikpapan.

[3] Pulkrabek, Willard W., Engineering Fundamentals of the Internal Combustion Engine, Second Edition, Prentice Hall, New Jersey.

[4] Soenarta, Nakoela., 1985, Motor Serba Guna, Pradnya Pramita, Jakarta.

[5] Suyanto, Wardan., 1989, Teori Motor Bensin, Proyek Pengembangan Pendidikan DEPDIKBUD, Jakarta. 